\title{
Long Non-Coding RNA MALAT1 Contributed to the Proliferation of PNH Clone in Paroxysmal Nocturnal Hemoglobinuria Patients
}

\author{
Uzun Kodlama Yapmayan RNA, MALAT1, Paroksismal Noktürnal Hemoglobinüri Hastalarında \\ PNH Klonal Proliferasyonuna Katkı Sağlar
}

\author{
(D) Honglei Wang*, (D) Yingying Chen*, (D) Hui Liu, (D) Zhaoyun Liu, (D) Rong Fu \\ *These authors contributed equally to this work. \\ Tianjin Medical University General Hospital, Department of Hematology, Tianjin, China
}

\section{To the Editor,}

Paroxysmal nocturnal hemoglobinuria (PNH) is an acquired clonal disorder of hematopoietic stem cells caused by somatic mutation of the phosphatidylinositol glycan A gene (PIG-A) on chromosome Xp22.1 [1]. The PIG-A mutation is necessary but insufficient to explain PNH clone proliferation. The mechanism of the proliferative advantage of the PNH clone has not yet been clarified. At present, studies on the mechanism of PNH clone proliferation are mainly focused on protein-coding genes, while the function and clinical significance of non-coding RNAs (ncRNAs), and in particular long ncRNAs (LncRNAs), in PNH remain unknown. MALAT1 is one of the most extensively studied LncRNAs. It was found localized in the nucleus and expressed in a variety of tissues [2]. MALAT1 can regulate cell proliferation, differentiation, apoptosis, migration, and autophagy, among others [3]. MALAT1 has been demonstrated to be involved in many cancers, cardio-cerebrovascular disease, and hematological malignancies. However, knowledge of the action of MALAT1 in PNH is still lacking. The purpose of our study was to investigate the role of MALAT1 in PNH clone proliferation and to find a new therapeutic direction for $\mathrm{PNH}$.

A total of $30 \mathrm{PNH}$ patients, including $22 \mathrm{PNH}$ patients and 8 aplastic anemia (AA)-PNH patients, were enrolled in our study according to international PNH Study Group Criteria [4]. CD59and $\mathrm{CD}_{59}{ }^{+}$granulocytes and monocytes were obtained by flow cytometry (Figures 1A and 1B). MALAT1 expressions were verified for these $30 \mathrm{PNH}$ patients by quantitative real-time polymerase chain reaction (qRT-PCR). The clinical features of the PNH patients, primers of MALAT1, and methods of cell sorting and QRT-PCR are available from the authors as supplementary data. Correlations were analyzed with clinical indexes, including hemoglobin $(\mathrm{Hb})$, white blood cell count (WBC), platelet count $(\mathrm{PLT})$, reticulocytes (Ret), lactate dehydrogenase $(\mathrm{LDH})$, total bilirubin (TBIL), and PNH clones.

As the results of qRT-PCR showed, MALAT1 $(3.070 \pm 2.503)$ expressions in $\mathrm{CD}^{-} 9^{-}$cells were consistently higher than those in CD59+ cells $(1.281 \pm 1.246, p=0.0004)$ among these $30 \mathrm{PNH}$ patients (Figure 1C).

High expression of MALAT1 was negatively correlated with $\mathrm{Hb}$ level $(r=-0.3894, p=0.0334)$ and positively correlated with the percentage of Ret $(r=0.4481, p=0.0168)$, LDH levels $(r=0.6244$, $\mathrm{p}=0.0307)$, and CD59- granulated and monocyte cell ratio $(r=0.5188, p=0.0049)$ (Figure 1D).

The level of MALAT1 in PNH clone cells was found to be significantly increased and was correlated with clinical indicators of PNH. The molecular functions of MALAT1 include alternative splicing, transcriptional regulation, and competing endogenous RNA functions. MALAT1 was shown to bind alternative splicing factor SRSF1 in hepatocellular carcinoma development [5]. In another study, MALAT1 promoted the proliferation and imatinib resistance of chronic myeloid leukemia cells via the MALAT1/miR-328 axis [6]. MALAT1 downregulated miR-181a-5p through the Hippo-YAP signaling pathway, resulting in regulation of myeloma cell proliferation [7]. MALAT1 could also induce tolerogenic dendritic cells and immune tolerance in autoimmune diseases by regulating the miRNA-155/DC-SIGH/IL10 axis [8]. These results illustrate that MALAT1 plays an important role not only in malignant tumors but also in benign diseases.

The characteristics of clonal dynamics and selection forces of PNH clones are similar to those of tumors. Thus, we predict that MALAT1 may have an important function in contributing to proliferation advantages and restraining apoptosis in PNH progression. The mechanism remains to be further studied.

Keywords: Paroxysmal nocturnal hemoglobinuria, LncRNA, Clone proliferation, MALAT1

Anahtar Sözcükler: Paroksismal noktürnal hemoglobinüri, LncRNA, Klonal proliferasyon, MALAT1

Informed Consent: Our study complied with the International Ethical Guidelines for Biomedical Research Involving Human Subjects (2002) developed by the Council for International Organizations of Medical Sciences (CIOMS) in collaboration 
A
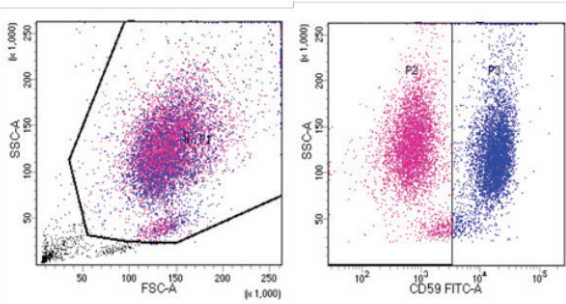

B
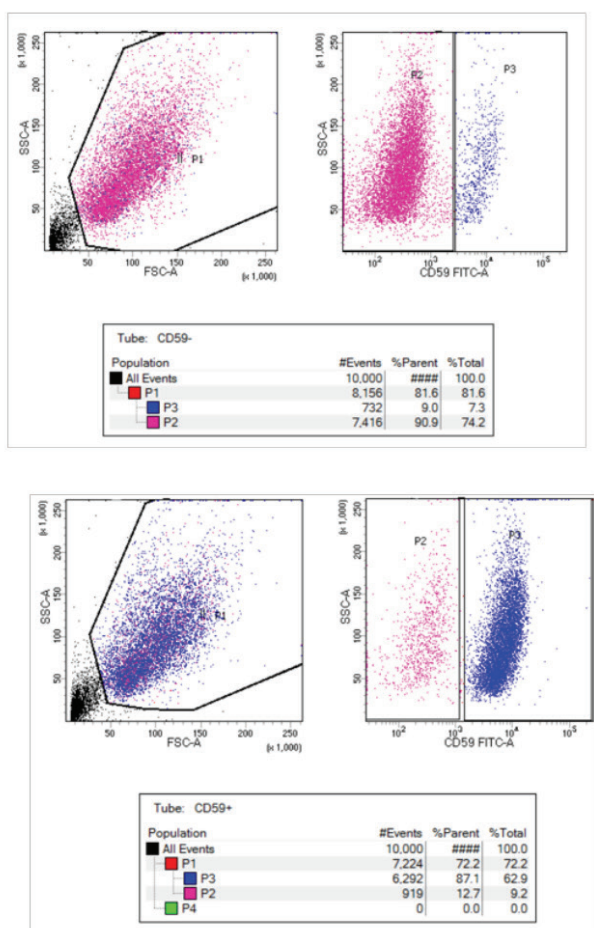

C

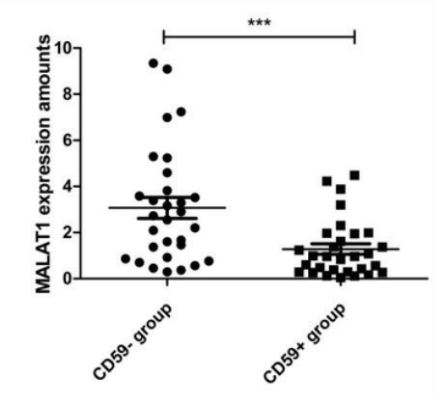

D
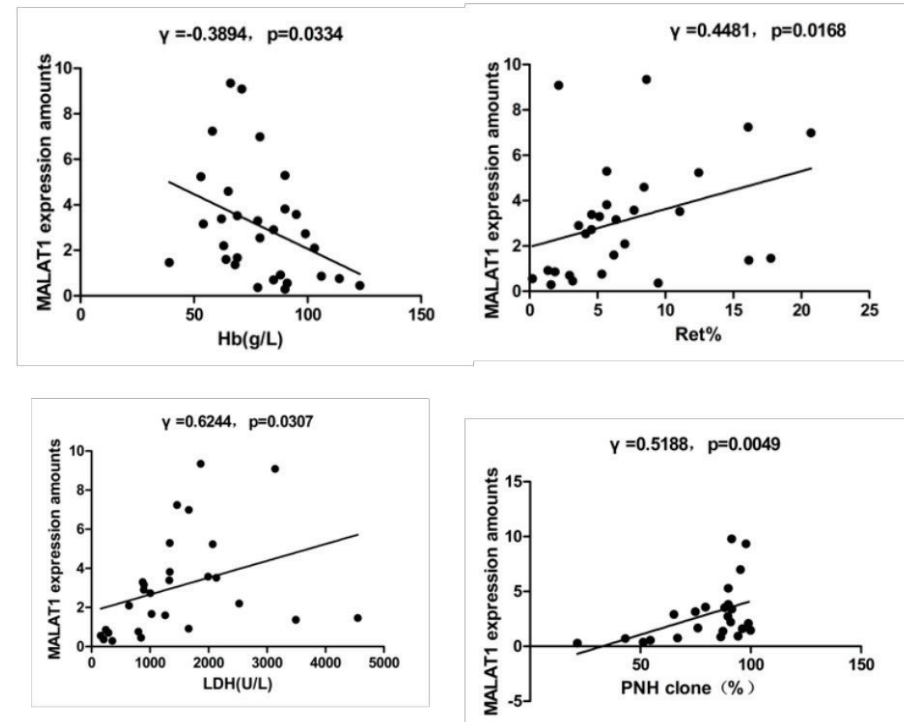

Figure 1. A) The cells of $30 \mathrm{PNH}$ patients were sorted by flow cytometry to obtain CD59- and CD59+ granulocytes and monocytes. Granulocytes and monocytes were selected as sorting objects in the first flow diagram, and CD59- (P2) and CD59+ (P3) granulocytes and monocytes were selected in the second flow diagram by CD59 sorting. B) Sorting purity of the CD59- and CD59 ${ }^{+}$granulocytes and monocytes. The sorting purity is about 90\%. C) MALAT1 expression of the CD59- and CD59+ cells in 30 PNH patients. D) Correlation analysis between MALAT1 expression and clinical data. The expression of MALAT1 was negatively correlated with the proportion of the level of $\mathrm{Hb}$ and positively correlated with the percentage of Ret, LDH levels, and the proportion of PNH clones.

with the World Health Organization (WHO) and was approved by the Ethics Committee of Tianjin Medical University.

\section{Authorship Contributions}

Design: R.F.; Data Collection or Processing: H.W., Y.C., H.L., Z.L.; Writing: H.W., Y.C.

Conflict of Interest: No conflict of interest was declared by the authors.

Financial Disclosure: This work was supported by the National Natural Science Foundation of China (Grant nos. 81770110, 81900131, 82000128), the Tianjin Municipal Natural Science Foundation (Grant nos. 18JCYBJC27200, 18JCONJC80400), and the Tianjin Education Commission Research Project (2018KJ043, 2018KJ045).

\section{References}

1. Hill $A$, DeZern $A E$, Kinoshita $T$, Brodsky RA. Paroxysmal nocturnal haemoglobinuria. Nat Rev Dis Primers 2017;3:17028.

2. Lei L, Chen J, Huang J, Lu J, P ei S, Ding S, Kang L, Xiao R, Zeng Q. Functions and regulatory mechanisms of metastasis-associated lung adenocarcinoma transcript 1. J Cell Physiol 2018;234:134-151.

3. Zhang $\mathrm{X}$, Hamblin $\mathrm{MH}$, Yin KJ. The long noncoding RNA Malat1: its physiological and pathophysiological functions. RNA Biol 2017;14:17051714.

4. Parker $C$, Omine $M$, Richards $S$, Nishimura J, Bessler $M$, Ware $R$, Hillmen P, Luzzatto L, Young N, Kinoshita T, Rosse W, Socié G; International PNH Interest Group. Diagnosis and management of paroxysmal nocturnal hemoglobinuria. Blood 2005;106:3699-3709.

5. Malakar P, Shilo A, Mogilevsky A, Stein I, Pikarsky E, Nevo Y, Benyamini $H$, Elgavish S, Zong X, Prasanth KV, Karni R. Long noncoding RNA MALAT1 promotes hepatocellular carcinoma development by SRSF1 upregulation and mTOR activation. Cancer Res 2017;77:1155-1167. 
6. Wen $F$, Cao YX, Luo ZY, Liao P, Lu ZW. LncRNA MALAT1 promotes cell proliferation and imatinib resistance by sponging miR-328 in chronic myelogenous leukemia. Biochem Biophys Res Commun 2018;507:1-8.

7. Sun $Y$, Jiang T, Jia Y, Zou J, Wang $X$, Gu W. LncRNA MALAT1/miR-181a-5p affects the proliferation and adhesion of myeloma cells via regulation of Hippo-YAP signaling pathway. Cell Cycle 2019;18:2509-2523.
8. Wu J, Zhang $H$, Zheng $Y$, Jin $X$, Liu M, Li S, Zhao Q, Liu X, Wang Y, Shi M, Zhang $S$, Tian J, Sun Y, Zhang M, Yu B. The long noncoding RNA MALAT1 induces tolerogenic dendritic cells and regulatory T cells via miR155/dendritic cellspecific intercellular adhesion molecule-3 grabbing nonintegrin/IL10 axis. Front Immunol 2018;9:1847.

๑Copyright 2021 by Turkish Society of Hematology

Turkish Journal of Hematology, Published by Galenos Publishing House

Address for Correspondence/Yazışma Adresi: Rong Fu, M.D., Tianjin Medical University General Hospital,

Department of Hematology, Tianjin, China

Phone : (086) 02260817181

E-mail : florai@sina.com ORCID: orcid.org/0000-0002-9928-9224
Received/Geliş tarihi: January 22, 2021 Accepted/Kabul tarihi: March 16, 2021

DOI: 10.4274/tjh.galenos.2021.2021.0065

\section{Supplemental Table 1. Clinical characteristics of 30 paroxysmal nocturnal hemoglobinuria patients.}

\section{Characteristics \\ Values}

Total no. of patients

Gender, M/F

Age, years, median (range)

Clinical classification, $\mathrm{n}(\%)$

Classical PNH

AA-PNH

History of thrombosis, $\mathrm{n}(\%)$

$\mathrm{Hb}(\mathrm{g} / \mathrm{L})$

Ret $(\%)$

WBC $\left(\times 10^{9} / \mathrm{L}\right)$

$\operatorname{PLT}\left(\times 10^{9} / \mathrm{L}\right)$

TBIL $(\mu \mathrm{mol} / \mathrm{L})$

LDH (U/L)

Granulocyte CD59- (\%)

Erythrocyte CD59- (\%)

PNH: Paroxysmal nocturnal hemoglobinuria; AA-PNH: aplastic anemia-paroxysmal nocturnal hemoglobinuria; Hb: hemoglobin; Ret: reticulocytes; WBC: white blood cell count; PLT: platelet count; TBIL: total bilirubin; LDH: lactate dehydrogenase.

\section{Supplemental Table 2. Gene primer sequences.}

Gene

MALAT1

GAPDH

\section{Forward}

GCAGCAGTTCGTGGTGAAGATAGG

CAGGAGGCATTGCTGATGAT

Reverse

Annealing temperature, ${ }^{\circ} \mathrm{C}$

30

$19 / 11$

41 (16-68)

22 (73.33)

8 (26.67)

11 (36.67)

$79.71 \pm 23.97$

$8.285 \pm 5.589$

$5.47 \pm 3.29$

$116.00 \pm 95.03$

$34.53 \pm 18.59$

$1543.00 \pm 1181.0$

$74.90 \pm 24.39$

$47.50 \pm 31.77$

ICGCCTCCTCCGTGTGGTG

58.0

